\title{
Multivariate Optimization Techniques for Optimizing Capillary Electrophoretic Method
}

\section{Ismail Murat Palabiyik*}

Department of Analytical Chemistry, Faculty of Pharmacy, University of Ankara, 06100 Tandogan, Ankara, Turkey

Separation sciences have been saved their popularity in this century with different kind of techniques in terms of applicability in a wide range of scientific area like as pharmaceutical, environmental, food, forensic, proteomic, genomic and metabolamic analysis. Easily connections with different detector types are provided lower detection and quantitation limit especially analyzing process in biological samples. Chromatographic and electrophoretic methods are most usable techniques with their advantages. Capillary electrophoresis is come into prominence from other separation techniques having small sample volume, few volumes of consuming run buffer, studying in wide $\mathrm{pH}$ range and obtaining high theoretical plates.

Optimization is the most important part in analytical methods development. Different factors in different techniques are effected the results obtained from an analytical device. Traditionally, one factor at a time approach is used for testing an effect of only one factor on experimental responses. However, this application is time consuming and isn't allowed to obtain the interaction between other factors. To overcome this problem, multivariate optimization techniques have been widely used. These are combination of mathematical and statistical techniques for interpreting the relationship between responses and factor effects simultaneously and optimizing the levels of variables to reach the optimum system performance. To achieve these, different design of experiments charts established by different level of the investigating experimental factors are used.

Buffer $\mathrm{pH}$, concentration of the run buffer, applied voltage, length and diameter of capillary, temperature and injection pressure and types are experimental variables having an effect on response from capillary electrophoresis device such as effective mobility, peak shape or asymmetry. Helping with multivariate optimization techniques, interactions between of these factors on experimental responses were investigated simultaneously with a suitable design of experiment chart without time-consuming.

Finally, Pharmaceutica Analytica Acta could contribute to this field in separation sciences with its published article about this subject and provide a scientific media for sharing the knowledge.
*Corresponding author: Dr. Ismail Murat Palabiyik, Department of Analytical Chemistry, Faculty of Pharmacy, University of Ankara, 06100 Tandogan, Ankara Turkey, Tel: +903122033172; GSM: +905354822135; Fax: +903122131081; E-mail: academ3000@yahoo.com

Received December 23, 2011; Accepted December 29, 2011; Published December 31, 2011

Citation: Palabiyik IM (2011) Multivariate Optimization Techniques for Optimizing Capillary Electrophoretic Method. Pharm Anal Acta 2:109e. doi:10.4172/2153 2435.1000109e

Copyright: @ 2011 Palabiyik IM. This is an open-access article distributed under the terms of the Creative Commons Attribution License, which permits unrestricted use, distribution, and reproduction in any medium, provided the original author and source are credited. 